\title{
Study of undisturbed loess stress-strain experiments based on CT
}

\author{
Zhaoyang Wang \\ College of Geology \& Environment, Xi'an University of Science and Technology, Xi'an, China \\ wangzhaoyang1999@126.com
}

Keywords: undisturbed loess; damage; stress-strain.

Abstract. Test method for observation of geotechnical material in structural damage has become one of the hot field of mechanics, which is the basis to establish the structural model. The authors use real time CT test of triaxial stress in undisturbed loess during triaxial shear tests - strain were studied. The paper analyzes the $\mathrm{Q}_{2}$ and $\mathrm{Q}_{3}$ loess stress - strain curves, proposed initial damage stress undisturbed loess method of determining the threshold of strain. Based on the test results, it indicates $\mathrm{Q}_{2}$ compared $\mathrm{Q}_{3}$ depressed loess prone to injury at low confining, and its strain injury threshold lower than the $\mathrm{Q}_{3}$ loess. On this basis, the damage variable formula proposed by the number of CT defined fitting draw damage variable axial strain and deviatoric stress relationship. CT triaxial test instrument can reveal undisturbed loess structural damage evolution and deformation and destruction law. The instrument is a powerful tool for in-depth analysis of the mechanical properties of the soil.

\section{Introduction}

In recent years the micro, meso and macro tests proved the geotechnical material is a natural damage material. The core issues of the 21 st century soil mechanics is a mathematical model of soil structural (Shen. 1996 ). Test method for observation of geotechnical material in structural damage has become one of the hot field of mechanics, which is the basis to establish the structural model. Liu et al., (2005) has established the Lanzhou frozen loess uniaxial compression damage constitutive model by using the dynamic CT test. Lu et al.,

(2002) used the CT machine supporting of unsaturated triaxial apparatus, the dynamic, quantitative and without damage research on unsaturated undisturbed expansive soil in triaxial shear test process, which test soil samples obtained internal structural damage clearly Ctimages and corresponding data. Huang et al., (2004) studied the mechanical properties of red clay under triaxial stress conditions using CT technology. Under triaxial stress conditions Sun et al., (2005) tested chacteristics of Shanghai clay by means of a CT machine.

CT technology has the following advantages (Chen et al., 2001): (1)change dynamically, quantitative and non-destructive measurements of the internal structure of the material in the course of the force; (2)get a thin layer density distribution, there is the problem of overlapping objects around defects , and three-dimensional objects into a different sheet in accordance with image data; (3) large detection area and high resolution. which the resolution is the main indicator ofCT machine performance. CT machine spatial resolution in this article is $0.35 \mathrm{~mm} \times 0.35 \mathrm{~mm}$, volume resolution of $0.12 \mathrm{~mm}^{3}$ (thickness $1 \mathrm{~mm}$ ), the density contrast resolution of $0.3 \%$ (3 HU).

\section{CT triaxial test of undisturbed loess}

The use of state key laboratory of frozen soil engineering CT apparatus, undisturbed loess was undrained shear tests, while the sample section CT scan, observe internal structural changes . The soil samples for the $\mathrm{Q}_{3}, \mathrm{Q}_{2}$ undisturbed loess, with undisturbed sample is made of soil height of $12.5 \mathrm{~cm}, 6.18 \mathrm{~cm}$ diameter sample.

In triaxial pressure chamber, undisturbed loess were first prepared consolidation, to be stable deformation, triaxial shear test. Shear rate is $0.3 \mathrm{~mm} / \mathrm{min}$. After the consolidation is complete and in the initial 
state of the sample, the sample were three layers of scanning of $2 \%, 5 \%, 8 \%, 10 \%$ and $19 \%$ of each stage. Three aliquots of the scanning position in the sample, and track scanning section scanning, location divided into three sections. Before shearing the basic parameters of soil samples and test conditions are shown in table 1. During the scanning process scans each corresponding stress - strain state in table 2.

Table 1 Initial conditions and parameters before shear test

\begin{tabular}{cccc}
\hline \multirow{2}{*}{ soil } & $\begin{array}{c}\rho \\
/\left(\mathrm{g} / \mathrm{cm}^{3}\right)\end{array}$ & $\begin{array}{c}w \\
/ \%\end{array}$ & $\begin{array}{c}p \\
\mathrm{kPa}\end{array}$ \\
\hline $\mathrm{Q}_{2}$ loess & 1.61 & 15.82 & 70 \\
$\mathrm{Q}_{3}$ loess & 1.44 & 13.89 & 70 \\
\hline \multicolumn{3}{c}{ Table 2 Stress-strain data of each scanning } \\
\hline \multirow{2}{*}{ Strain/ \% } & \multicolumn{3}{c}{$q / \mathrm{kPa}$} \\
\cline { 2 - 3 } & $\mathrm{Q}_{3}$ loess & $\mathrm{Q}_{2}$ loess \\
\hline 2 & 118.32 & 313.13 \\
5 & 201.76 & 329.91 \\
8 & 241.85 & 394.21 \\
10 & 272.00 & 414.56 \\
19 & 387.83 & 549.25 \\
\hline
\end{tabular}

\section{stress - strain analysis and determination of damage variable}

\section{Stress - strain analysis}

Deviatoric stress and axial strain curves of undisturbed loess shown in figure 1.

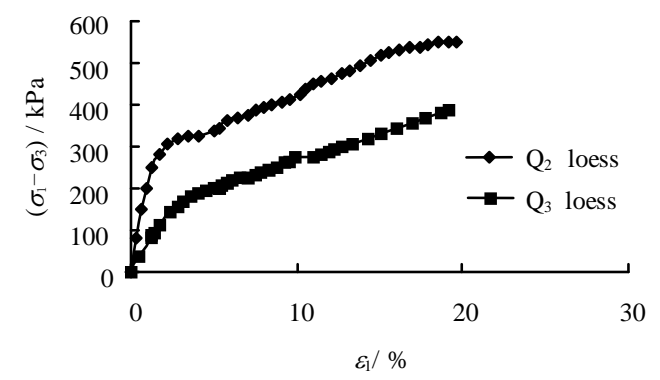

Fig .1 deviatoric stress versus strain of $Q_{3}$ and $Q_{2}$ loesses under $70 \mathrm{kPa}$ confining pressure

As can be seen from the figure 1, undisturbed $\mathrm{Q}_{3}$ loess stress - strain curve is a tough type of stress strain curve, the deformation curve $\mathrm{Q}_{2}$ loess weak hardening stress - strain curve, both plastic failure. $\mathrm{Q}_{2}$ loess intensity was significantly higher than $\mathrm{Q}_{3}$, which is due to $\mathrm{Q}_{2}$ loess dense structure, high bond strength due to the particles.

\section{$\mathbf{Q}_{3}$ undisturbed loess stress - strain relations}

For $\mathrm{Q}_{3}$ undisturbed loess, available in the form of a power function curve fitting test, then:

$$
\left(\sigma_{1}-\sigma_{3}\right)=\beta \varepsilon_{1}^{\alpha}
$$

Different tangent modulus stress level $E_{\mathrm{t}}$

$$
E_{\mathrm{t}}=\frac{\mathrm{d}\left(\sigma_{1}-\sigma_{3}\right)}{\mathrm{d} \varepsilon_{1}}=\beta \alpha \varepsilon_{1}^{\alpha-1}=\alpha \beta^{\frac{1}{\alpha}}\left(\sigma_{1}-\sigma_{3}\right)^{1-\frac{1}{\alpha}}
$$

Where $\alpha$ and $\beta$ are experimental constants, functions as the confining pressure $\sigma_{3}$. The test data $\left(\sigma_{1}-\sigma_{3}\right)$ and $\varepsilon_{1}$ are plotted in double logarithmic coordinates, as shown in fig 2 . The relationship is approximately a straight line, $\lg \beta$ and $\alpha$ respectively, the linear slope distance and gradient. 


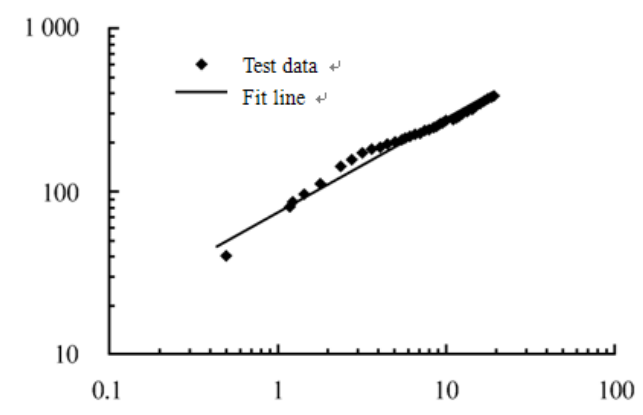

Fig.2 $\lg \left(\sigma_{1}-\sigma_{3}\right)$ versus $\lg \varepsilon_{1}$

Figure. 2 shows $\beta=6.57 \times 10^{7}, \quad \alpha=0.69$. Therefore tangent modulus $E_{\mathrm{t}}=4.53 \times 10^{7} \varepsilon_{1}^{-0.31}$.

\section{$\mathbf{Q}_{2}$ undisturbed loess stress - strain relations}

For $\mathrm{Q}_{2}$ undisturbed loess, stress - strain curves

$$
\left(\sigma_{1}-\sigma_{3}\right)=\frac{\varepsilon_{1}}{a+b \varepsilon_{1}}
$$

The formula can also be written as

$$
\frac{\varepsilon_{1}}{\left(\sigma_{1}-\sigma_{3}\right)}=a+b \varepsilon_{1}
$$

Tangent modulus of different stress levels $E_{\mathrm{t}}$

$$
E_{\mathrm{t}}=\frac{\mathrm{d}\left(\sigma_{1}-\sigma_{3}\right)}{\mathrm{d} \varepsilon_{1}}=\frac{a}{\left(a+b \varepsilon_{1}\right)^{2}}
$$

$a$ and $b$ are experimental constants as a function of $\sigma_{3}$. The test data are plotted in the coordinate system conversion $\varepsilon_{1} /\left(\sigma_{1}-\sigma_{3}\right)$ and $\varepsilon_{1}$, approximately linear relationship, as shown in fig. $a$ and $b$ respectively, the linear intercept and slope.

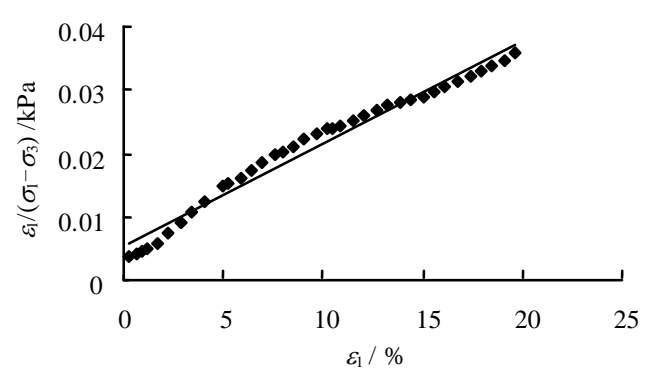

Fig.3 $\varepsilon_{1} /\left(\sigma_{1}-\sigma_{3}\right)$ versus $\varepsilon_{1}$

Figure 3 shows $a=0.0054, \quad b=0.0016$. Therefore tangent modulus is expressed as:

$$
E_{\mathrm{t}}=\frac{0.0054}{\left(0.0054+0.0016 \varepsilon_{1}\right)^{2}}
$$

\section{Determination of initial damage threshold of stress and strain}

Based on the stress-strain curves (Figure 1), there is a turning point marken circle which hints that it is possible to find out the initial damage point. At the initial loading stage, strain increase slowly, and then it increase rapidly with the increase in the stress after coming to turing point, plotted in the half-logarithm coordinate.

The $\mathrm{Q}_{3}$ and $\mathrm{Q}_{2}$ undisturbed loess triaxial test results, coming $\varepsilon_{1}-\lg \left(\sigma_{1}-\sigma_{3}\right)$ curve (Figure 4,5), which consists of some gentle curves and a steep drop straight lines. The point $\mathrm{O}$ is taken as the smallest radius of curvature, the point $\mathrm{C}$ is the intersection point of two tangents, and the bisector of angle $\angle \mathrm{OCB}$ is $\mathrm{CD}$. Then, 
the point $\mathrm{D}$ is considered as an initial damage point and the corresponding stress and strain are called the initial damage threshold of stress and strain.

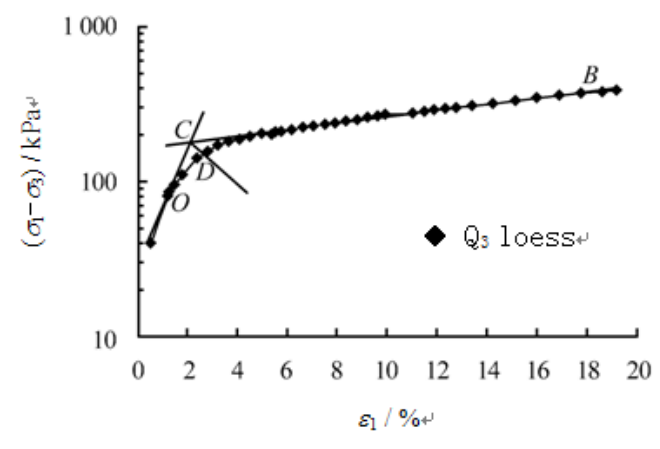

Fig .4 $\varepsilon_{1}$ versus $\lg \left(\sigma_{1}-\sigma_{3}\right)$ of $\mathbf{Q}_{3} \operatorname{loess}$

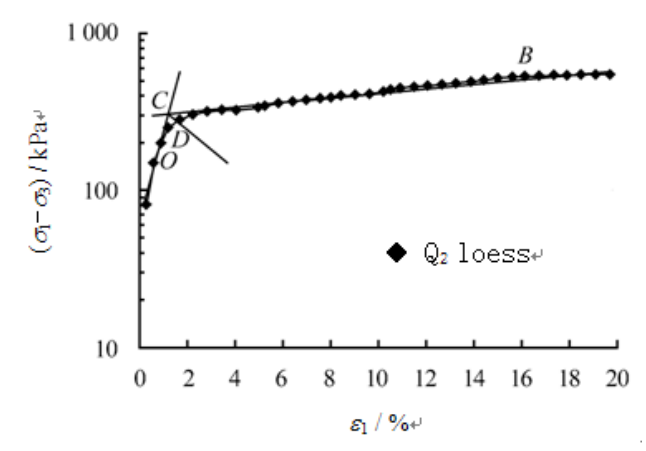

Fig .5 $\varepsilon_{1}$ versus $\lg \left(\sigma_{1}-\sigma_{3}\right)$ of $\mathbf{Q}_{2}$ loess

According to the above method, $\mathrm{Q}_{3}$ test soil samples to determine the initial bias stress damage is 160 $\mathrm{kPa}$, and strain threshold value is $2.6 \% . \mathrm{Q}_{2}$ initial sample bias stress damage is $280 \mathrm{kPa}$, and strain threshold value is $1.6 \%$.

Test $\mathrm{Q}_{3}$ and $\mathrm{Q}_{2}$ soil overburden gravity stress were 90 and $300 \mathrm{kPa}$, belongs normally consolidated soil. Confining pressure during the test to maintain $70 \mathrm{kPa}$, soil damage occurs and the axial stress $\mathrm{Q}_{2}$ and $\mathrm{Q}_{3}$ loess were 230 and $350 \mathrm{kPa}$ via the initial stress values. Experimental results show that the initial damage stress of loess is greater than the weight of overburden stress, which when added to the initial damage $\mathrm{Q}_{3}$ loess axial stress is far greater than the overlying weight stress. This is because the $\mathrm{Q}_{3}$ loess density, loose structure, more large pores. The beginning of the pressing $\mathrm{Q}_{3}$ compacted soil produced only soil particles are not shear displacement, its structure remained unchanged damage occurs. $\mathrm{Q}_{2}$ loess is density, while confining pressure test is small, the axial stress exceeds the overburden gravity stress a little, soil particles shear displacement occurs. Thus, $\mathrm{Q}_{2}$ loess is more prone to damage in the low confining pressure and strain threshold damage occurs correspondingly smaller.

\section{Determination of damage variable}

CT numbers variation of geotechnical materials under stress state can indicate the damage of the material. It can be established by the appropriate constitutive model to establish the relationship between CT number and damage variables.

First, we need derive the absorption coefficient $\mu$ and CT number of relationships. Set $\rho$ to material density, then:

$$
\mu_{\mathrm{m}}=\frac{\mu}{\rho}
$$

Where $\mu_{\mathrm{m}}$ is the mass attenuation coefficient through $1 \mathrm{~g}$ substance; $\mu$ is a linear attenuation coefficient of a substance through $1 \mathrm{~cm}$. Hounsfield British professor gives a definition CT numberss(Hounsfield et al., 1973). 


$$
H=\frac{\mu-\mu_{\mathrm{w}}}{\mu_{\mathrm{w}}} \times 1000
$$

Where $\mu_{\mathrm{w}}$ is the absorption coefficient of water, the water is concerned, $\rho=1$

Based on Eqs. (8), $H$ can be expressed as

$$
H=\frac{\mu-\mu_{\mathrm{w}}}{\mu_{\mathrm{w}}} \times 1000=\left(\frac{\mu}{\mu_{\mathrm{w}}}-1\right) \times 1000
$$

Based on $\mu_{\mathrm{w}}=1$, there:

$$
\begin{array}{r}
H=(\mu-1) \times 1000 \\
\mu=\frac{H}{1000}+1
\end{array}
$$

Mass attenuation coefficient of the mixture(Qiang, 2011):

$$
\mu_{\mathrm{m}}=\mu_{\mathrm{m} 1} \rho_{1}+\mu_{\mathrm{m} 2} \rho_{2}+\cdots \cdots+\mu_{\mathrm{m} i} \rho_{i}
$$

The formula: $\rho_{i}$ wherein the weight percentage of a certain component; component $\mu_{\mathrm{m} i}$ is a mass attenuation coefficient. Ray attenuation coefficient of the mixture can be written as:

$$
\mu=\rho \sum_{i=1}^{m}\left(\mu_{\mathrm{m} i} \rho_{i}\right)
$$

Soil absorption coefficient is expressed as:

$$
\mu=\rho\left(\rho_{1} \mu_{1}+\rho_{2} \mu_{\mathrm{w}}\right)=\rho\left(\frac{1}{1+\omega} \mu_{1}+\frac{\omega}{1+\omega} \mu_{\mathrm{w}}\right)=\gamma_{\mathrm{d}}\left(\mu_{1}+\omega \mu_{\mathrm{w}}\right)
$$

Substituting Eq.(14) into (10), we have:

$$
H=\left[\gamma_{\mathrm{d}}\left(\mu_{1}+\omega\right)-1\right] \times 1000
$$

Where: Equation $\omega$ is the water content of soil samples, $\gamma_{\mathrm{d}}$ soil samples of dry bulk density. According to the known statistical $\mathrm{Q}_{3}$ loess scan data to calculate the absorption coefficient $\mathrm{Q}_{3}$ loess particles (soil samples $5.5 \mathrm{~cm}$ ) were initially 1.3046 , to 1.4299 after the trial.

Bellion et al,(1978) proposed by the rate of change in the density of the material creep damage of $\Delta \rho / \rho$ to reflect the damage, and the mass conservation law proved the damage variable $D$ can be expressed as

$$
D=-\frac{\Delta \rho}{\rho_{0}}
$$

Davis (1966), Lemaitre (1978) and Belloni (1979), and so have to define damage variable material density measurement with damage, but the main difficulty is the amount of change is difficult to measure the density of $\Delta \rho$. Since the application of CT scanning equipment, to solve this problem.

Based on Eqs. (7), $\frac{\Delta \rho}{\rho_{0}}$ can be expressed as

$$
\frac{\Delta \rho}{\rho_{0}}=\frac{\Delta \mu}{\mu_{0}}=\frac{\mu_{i}-\mu_{0}}{\mu_{0}}
$$

Based on Eqs. (11),

$$
\begin{gathered}
\mu_{i}=\frac{H_{i}}{1000}+1 \\
\mu_{0}=\frac{H_{0}}{1000}+1 \\
\frac{\Delta \rho}{\rho_{0}}=\frac{H_{i}-H_{0}}{H_{0}+1000}
\end{gathered}
$$

Therefore, the definition of loess damage variable 


$$
D=-\frac{H_{i}-H_{0}}{H_{0}+1000}
$$

Where $H_{0}$ is the initial soil sample damage sectional CT number ME; ME value reflects the average density of all the material points of the selected area. $H_{i}$ is a cross-sectional CT test average number ME $i$ stages.

In order to facilitate changes of injury variables, taking the absolute value of the formula (21)

$$
D_{\mathrm{ME}}=\left|\frac{H_{0}-H_{i}}{H_{0}+1000}\right|
$$

Where $D_{\mathrm{ME}}$ is the damage variable by CT computed ME.

By Eqs. (22) calculated the damage variable is actually a relative value, its exact size of the initial sample size depends on soil tests. This paper selects $\mathrm{Q}_{2}$ and $\mathrm{Q}_{3}$ loess initial state average of CT scan three numbers section, as the initial state of the soil damage this test sectional CT number $H_{0}$. Curve test soil damage variable values calculated in Figure 6-9.

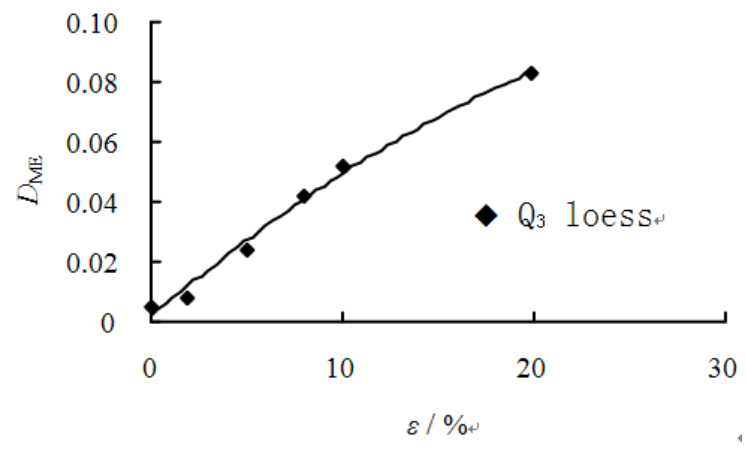

Fig .6 Damage variable $D_{M E}$ versus axial strain of loess $Q_{3}$

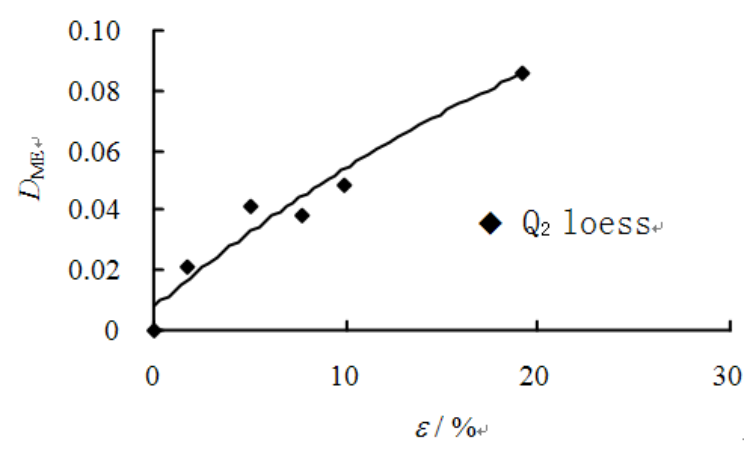

Fig .7 Damage variable $D_{\mathrm{ME}}$ versus axial strai of loess $Q_{2}$

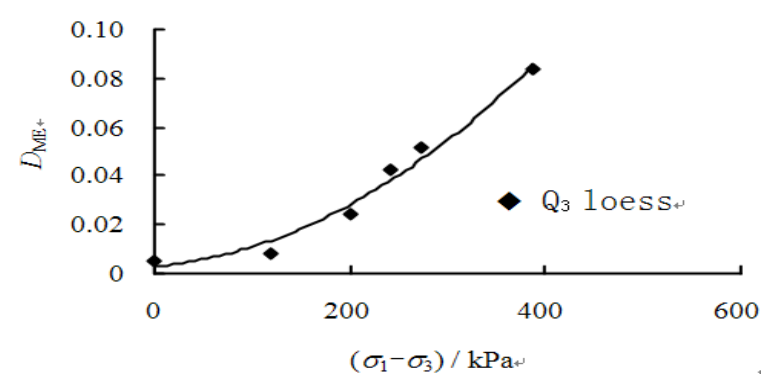

Fig .8 Damage variable $D_{\mathrm{ME}}$ versus deviatoric stress of loess $\mathbf{Q}_{3}$ 


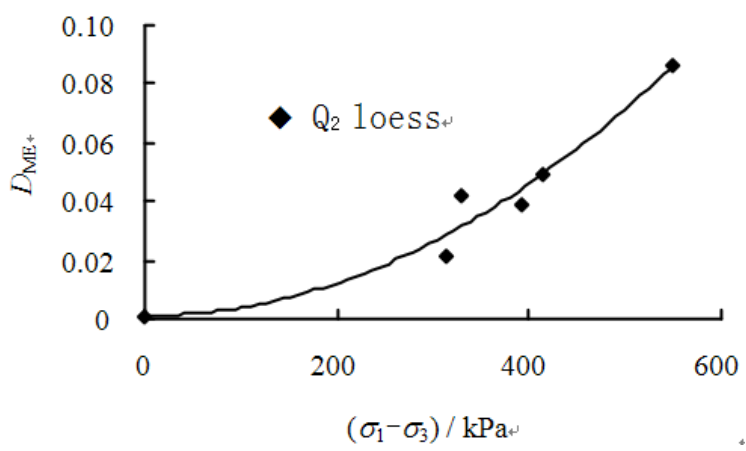

Fig .9 Damage variable $D_{\mathrm{ME}}$ versus deviatoric stress of loess $\mathbf{Q}_{2}$

According to the results, we can draw damage fitting a variable axial strain and deviatoric stress relation (1) $\mathrm{Q}_{3}$ loess

$$
\begin{gathered}
D_{\mathrm{ME}}=-7.0 \times 10^{-5} \varepsilon_{1}^{2}+0.0055 \varepsilon_{1}+0.0016 \\
D_{\mathrm{ME}}=5.0 \times 10^{-7}\left(\sigma_{1}-\sigma_{3}\right)^{2}+3.0 \times 10^{-5}\left(\sigma_{1}-\sigma_{3}\right)+0.0029
\end{gathered}
$$

(2) $\mathrm{Q}_{2}$ loess

$$
\begin{aligned}
& D_{\mathrm{ME}}=-6.0 \times 10^{-5} \varepsilon_{1}^{2}+0.0053 \varepsilon_{1}+0.0077 \\
& D_{\mathrm{ME}}=3.0 \times 10^{-7}\left(\sigma_{1}-\sigma_{3}\right)^{2}-2.0 \times 10^{-6}\left(\sigma_{1}-\sigma_{3}\right)+0.0012
\end{aligned}
$$

Eqs. (23) and (24) are loess damage variable expression of the strain and stress of bias, the result is equivalent to the same for the Eqs. (25) and (26) are also equivalent. As can be seen fromFigure 6-9, with the axial strain and deviatoric stress increases, soil damage variable increases. Loess damage variable and partial stress diagram, the two curves are reflected on a concave shape, initial damage value significantly greater than $\mathrm{Q}_{2}$ and $\mathrm{Q}_{3}$ loess, while damage variable $\mathrm{Q}_{3}$ loess and partial stress curve steeper slope large, reflect $\mathrm{Q}_{3}$ loess in the role of a partial change in stress injuries faster. In the same bias stress, $\mathrm{Q}_{3}$ loess damage variable value is significantly greater than $\mathrm{Q}_{2}$ loess. This reflects $\mathrm{Q}_{3}$ loess loose structure, prone to distortion and shear failure faster.

\section{Conclusion}

This paper analyzes the $\mathrm{Q}_{3}$ and $\mathrm{Q}_{2}$ undisturbed loess damage process by triaxial testing based on real time CT. This paper $r$ obtained the following conclusions.

(1) CT triaxial test instrument can reveal undisturbed loess structural damage evolution and deformation and destruction law. The instrument is a powerful tool for in-depth analysis of the mechanical properties of the soil.

(2) $\mathrm{Q}_{2}$ compared $\mathrm{Q}_{3}$ depressed loess prone to injury at low confining, and its strain injury threshold lower than the $\mathrm{Q}_{3}$ loess.

(3) Bias stress and strain threshold initial damage of the soil can be obtained by curve $\varepsilon_{1}$ and $\lg \left(\sigma_{1}-\sigma_{3}\right)$.

(4) Based on CT number undisturbed loess damage variable can be quantitatively reflect the degree of damage to the soil, Thus laying foundation for further study of the soil damage constitutive model.

\section{References}

[1] Zhu-jiang Shen. Mathematical model for soil mass structure - core problem of soil mechanics in the 21st century. Chinese Jounal of Geotechnical Engineering, 1996, 18(1): 95 - 97.

[2] Zeng-li Liu, Xiao-peng Zhang, Hongsheng Li. A damage constitutive model for frozen soils under uniaxial compression based on CT dynamic distinguishing. Rock and Soil Mechanics, 2005, 26(4): 542 - 546. 
[3] Zai-hua Lu, Zheng-han Chen, Yi-bin Pu. Study on damage evolution of natural expansive soil with computerized tomography during triaxial shear test. Journal of Hydraulic Engineering, 2002, (6): 106 - 112..

[4] Zhi-hong Huang, Li-jun Zhu, Yi-bin Pu, et al. CT analysis of dynamic change of mechanical properties of red clay under triaxial stress. Rock and Soil Mechanics, 2004, 25(8): 1215-1219.

[5] Hong Sun, Xiu-run Gg, Fu-jun Niu, et al. Real-time CT meso-testing on Shanghai silty clay subjected to triaxial loading. Chinese Journal of Rock Mechanics and Engineering, 2005, 24(24): 4559-4564.

[6] Zhen-han Chen, Zai-hua Lu, Yi-bin Pu. The matching of computerized tomograph with triaxial test apparatus for unsaturated soils. Chinese Jounal of Geotechnical Engineering, 2001, 23(4): : 387-392.

[7] Hounsfield G N. Computerized transverse axial scanning(tomography). British: The British Institute of Radiology, Stanford Libraries, 1973,46: 1016-1022.

[8] Tian-peng Qiang. Radiographic Inspection. Kunming: Yunnan Science \& Technology Press, 2001.

[9] BELLION G, BERNASCOIN G. In creep of engineering. Material \& Structure, 1978, 8(3): $54-65$.

[10] Davis P W. Cavity growth mechanism during creep. Act Melt, 1966, 14(9): 1138-1140.

[11] Lemaitre J.\&Chaboehe. J.L. Aspect phenomenologique de la Rupture Par Endommagement. J Mec, Appl, 1978, 2(3): 317-365.

[12] Belloni, G., Bernasconi, G., Piatti, G., eds. Creep damage models. Creep Eng Materials and Struct. Proc., Semin. Ispra(Verese)., London, 1979, 195-227. 